\title{
Safety Practices on Lead Poisoning Among Battery Technicians in Lagos Nigeria, 2017
}

\author{
Tajudeen Olusegun Rasheed ${ }^{1,}$, , Naoyo Mori ${ }^{2}$, Wasiu Adebowale Afolabi ${ }^{3}$, \\ Rukayat Ololade Abdul-Rasheed ${ }^{4}$ \\ ${ }^{1}$ Medical Department, Economic and Financial Crimes Commission, Ikoyi, Nigeria \\ ${ }^{2}$ Department of Public Health, Walden University, Minneapolis, USA \\ ${ }^{3}$ School of Post Basic Psychiatric/Mental Health Nursing, Federal Neuropsychiatric Hospital, Yaba, Nigeria \\ ${ }^{4}$ Tarukah Resources Consult, Agege, Nigeria
}

Email address:

rashtaj2005@yahoo.com (T. O. Rasheed)

${ }^{*}$ Corresponding author

\section{To cite this article:}

Tajudeen Olusegun Rasheed, Naoyo Mori, Wasiu Adebowale Afolabi, Rukayat Ololade Abdul-Rasheed. Safety Practices on Lead Poisoning Among Battery Technicians in Lagos Nigeria, 2017. Central African Journal of Public Health. Vol. 4, No. 1, 2018, pp. 27-33.

doi: 10.11648/j.cajph.20180401.15

Received: February 16, 2018; Accepted: March 9, 2018; Published: April 8, 2018

\begin{abstract}
Battery technicians need to maintain due diligence on safety practices at workplace to guide against lead poisoning, since preventive measures are the most cost-effective interventions against lead-related diseases. This study compared and investigated factors that influence battery technician's safety practices in Lagos, Nigeria. It was predicted that workplace conditions, blood lead levels and perceived risks could influence safety practices on lead poisoning. A quantitative, cross-sectional survey design, and systematic sampling were used to select $N=293$ adults aged 18 years and above. The instrument was validated and reliability established. The hypotheses were tested with chi-square and multiple logistic regression at $p<0.05$ and $95 \%$ CI. The finding on safety practices status of battery technicians is $20 \%$ and the use of personal protective equipment (PPE) 18\%. There was no significant difference between battery technicians in the organized and roadside settings considering perceived risk of lead poisoning and utilization of safety equipment.
\end{abstract}

Keywords: Battery Technicians, Safety Practices, Lead Poisoning, Nigeria

\section{Introduction}

Battery technicians are among the occupational groups who are exposed to lead poisoning because battery cells are made of lead [1]. Since this group is at the risk of exposure to lead poisoning, supporting their successful adherence to safety practices at the workplaces could protect their health and prevent them from developing lead-related diseases in the future [2]. Studies have reported that the estimated annual global burden of diseases that occurred due to lead poisoning is $0.6 \%$; and between 0.5 and 1.5 million of these cases happen among the occupationally exposed workers [3]. The incidence of lead poisoning remains a problem in developing countries considering the public health impact [4]. The population adjusted disease burden due to lead poisoning in Nigeria was estimated to be $2 \%$ from the regional analysis of the relative risk of the occupational diseases [5]. The category of diseases implicated in lead poisoning includes: gastrointestinal effect, hematological effect, nervous system effects such as intelligent quotient (IQ) defects, encephalopathy, wrist drop, hypertension, diabetes, and cancer due to prolonged exposure to lead toxin [6]. The routes through which battery technicians are exposed to lead poisoning include oral ingestion, dermal absorption and inhalation of lead fumes during smelting and smoldering the battery cells [7]. Therefore, battery technicians need to maintain due diligence on safety practices to guide against lead toxins, since preventive measures are the most costeffective interventions against lead-related diseases [8]. In the past years, and up to December 2015, there was a permissible exposure limit for blood lead levels of occupationally exposed workers [9]. But recent studies 
indicated that there is "no safe limit value", and the suggested limit value for case definition of elevated blood lead level (EBLL) in adults exposed to lead poisoning at the workplace is currently put at $\leq 5.0 \mu \mathrm{g} / \mathrm{dL}[10-12]$. This research regarding safety practices on lead poisoning among battery technicians illuminates important findings and no research was found that examined safety practices at the workplaces of battery technicians to guide against the elevation of blood lead level in Lagos, Nigeria. Instead, researchers have carried out studies that compared the blood lead levels of different automobile technicians that were exposed to lead poisoning. This study fills the gap in knowledge as it focuses on safety practices on lead poisoning, workplace conditions, blood lead levels, utilization of personal protective equipment (PPE) and perceived risk. It also compares the safety practices of battery technicians in the organized and roadside workshop settings.

\section{Materials and Methods}

\subsection{Research Design}

This study was a quantitative, cross-sectional survey design and multistage method was used to delimit the size of the population studied. Systematic sampling technique was used to select $N=293$ adults battery technicians aged 18 years and above who participated in this study. The study was conducted in Lagos, Nigeria, West Africa. Data were collected for 6 weeks from the participants whose workshop are located in the organized $(n=148,50.5 \%)$ and roadside ( $n=145,49.5 \%)$ settings of the two selected local government councils (Ikeja and Agege). Structured questionnaires with close-ended questions were administered to the participants to collect data. A test re-test pilot study was conducted at interval of 2 weeks to ascertain the validity and reliability of the self-developed instrument before it was used for the main study. The validity of the instrument was determined and the empirical, face, content and construct validity were appropriate. The Cronbach's Alpha analysis result of the pilot study confirmed the reliability of the instrument with high coefficient value of 0.8 .

\subsection{Sample Size and Sampling Procedure}

At the beginning of this study in January 2017, the sample size analysis was carried out to determine the appropriate number of subjects that could provide accurate representation of the participants studied. Peduzzi et al. [13] guideline for a minimum number of subjects to be included in a study using a logistic regression statistical model for analysis was adapted to calculate the sample size for this study and we got $N=250$ as minimum sample frame using the formula $N=10$ $K / p$ but $N=293$ participants were sampled to increase the study statistical power to.90. Rudestam and Newton [14] defined sampling as a strategy used to select a subset of the population being studied. Multistage sampling method was used to delimit and divide the population size of each of the two selected local government council into tertiary units (5 geographical zones) first and this comprised (North, South, East, West and Central geographic zones). The tertiary units were divided into secondary units (10 district areas); and the districts areas were further delimited into 100 wards each to make up the primary units (individual levels). Upon completion of the division of the large population, the systematic sampling technique was used to select the participants studied at the primary units. The sampling interval for this study was calculated by dividing the total population of the battery technician's workshops in the 5 geographical zones of the selected local government council areas with the number of the workshops to be sampled using the formula;

$$
K=\frac{\mathrm{N}}{\mathrm{n}}
$$

$K$ : the sample interval.

$N$ : the total population of workshops in the 5 geographical zones of the 2 selected local government councils.

$n$ : the number of workshops sampled in the study areas.

$$
\begin{gathered}
K=\frac{\mathrm{N}=5000(\text { Total Population of Workshops })}{\mathrm{n}=300(\text { No of Workshops sampled })} \\
K=16.666666667
\end{gathered}
$$

The population was not exactly divisible; the starting point for the study was between 0 and 16.666. The sample interval (16.666) was rounded up to the next integer, which is 17 . It was assumed that the starting point for the systematic random sampling was 3.6; then, the workshops were selected at an interval of $4,17,30,43$, and 56 . The interval value was added at every point in the population until the sample frame that corresponds with the sample population was selected. The processes were continued until the 100 wards with 10 units in each of the 5 geographical zones were sampled.

\subsection{How Data Were Collected and Measured}

The participants were invited and requested to complete the consent form freely before filling out the questionnaire. The questionnaire is of 4 pages on A4 paper and it contains 44 structured close-ended questions with estimated 30minutes fill out time. Data were collected from the participants daily for 6 weeks using the questionnaire. The data collected included the demographic and occupational characteristics of the subjects like the age, marital status, income, year of experience, level of education, and location of workshop. In the subsequent sections, the questions cover each hypothesis tested: workplace condition, blood lead levels, perceived risk of lead poisoning and the rate of utilization of PPE. Safety practices status was measured by the availability of safety materials and the rate of utilization of PPE at the workplace through recall reported in the questionnaires. Battery technicians' compliance with safety practices was measured by recall of the rate of utilization of PPE at workplace and a comparison of the safety practices in the organized and roadside setting measured with the recall. 


\subsection{How Scores Were Calculated}

The questions in the instrument were close-ended questions without multiple choice answers. The subject rating was either "YES" for positive response and "NO" for negative response. The response was scaled from $0-1$ using Guttman scale of response. The response was coded in which " 1 " stands for a correct answers while " 0 " stands for the wrong answer. The method of scoring adopted for the level of safety practices on lead poisoning was that participants who scored 9 points and above out of the 13 questions, that is $(\geq 70 \%)$ were rated good practices while participants who scored $<6$ points $(<50 \%)$ out of the 13 questions on safety practices section were rated poor. For questions on knowledge, the scoring method and categorization system was adopted in which participants who scored $<3$ points $(<50 \%)$ out of the 6 questions on knowledge section were rated to have poor knowledge of lead poisoning safety and participants who scored $\geq 5$ points and above out of the 6 questions that is ( $\geq 70 \%$ ) were rated to have good knowledge of lead poisoning safety practices.

\subsection{Data Analysis}

Descriptive analysis was used to examine the distribution of each variable while Chi-square $X^{2}$ and Fisher's exact test were used to examine the relationship that exists between the independent and dependent variables [15]. The multiple logistic regressions analysis was used to predict the most significant independent variable associated with lead poisoning safety practices. Backward stepwise multiple regression analysis was used to identify all independent variables related to the outcome variable at a $p$-value of $<$ 0.05 and $95 \%$ Confidence Interval after adjusting for the age, education, marital status, years of experience, monthly income, and knowledge of the importance of lead poisoning safety practices.

\subsection{Ethical Procedures and Protection of Participants' Rights}

This study was conducted after receiving approval from Institution Review Board (IRB) of Walden University, and the approval number is 12-05-16-0462777. All the procedures performed during the conduct of this study followed the standard stipulated in the studies involving human participants. The consent form was given to the participants to read and understand; and they filled it freely without any interference before participation in the study. The purpose was to seek the consent of the participants freely and explaining the nature of the study. Also, it was aimed at informing them that the survey would not bring any harm, but it could help them to improve their safety practices at workplaces. The participant's personal identifiers were not collected during data gathering process, and confidentially were maintained throughout the conduct of this study.

\section{Results}

\subsection{Demographic and Occupational Variables}

A total of $N=293$ battery technicians were surveyed. In Table 1 , there were $n=148$ of $293,50.5 \%$ battery technicians from the organized workplace setting while there were $n=145$ of $293,49.5 \%$ from the roadside workplace setting. The mean age of the $N=293$ participants were $43.6 \pm 10.5$ and $40.5 \pm 7.6$ years for the organized and roadside group respectively. Also, in Table 1, the finding shows that a significant association exists between safety practices on lead poisoning and education level of the participants at $X^{2}=$ $27.13, \mathrm{df}=1, p<0.000$ at $95 \%$ confidence interval.

\subsection{Workplace Conditions and Safety Practices}

Table 2 reported findings on workplace conditions and it shows that battery technicians who washed their hands with soap and water before eating, drinking, smoking and chewing were 9.4 times more likely to comply with lead poisoning safety practices at the workplace compared to battery technicians who did not wash their hands before eating, drinking, smoking and chewing with AOR: 9.4, 95\% CI: 2.07-42.95, $p<0.010$. The battery technicians who reported regular use of respirator while working on battery lead cells were 5.3 times more likely to protect themselves from inhalation of lead fumes/dust at the workplace compared to battery technicians who did not use respirator while working on battery lead with $A O R$ : 5.3, 95\% CI: 1.45-19.04, $p<$ 0.021. Furthermore, the results indicated that battery technicians who wore overall protective clothes to protect their bodies from contact with lead dust or spills of lead solution while working were 12.9 time more likely to adhere to safety practices on lead poisoning compared to the battery technicians who did not wear overall protective clothes at workplace with AOR: 12.9, 95\% CI: 2.94-56.8, $p<0.002$. Overall, there were significant association between variables of the workplace conditions and safety practices at $p<0.05$.

\subsection{Blood Lead Levels and Safety Practices}

In Table 3, the mean blood lead level of battery technicians in this study for the organized setting was $61.2 \pm 13.6 \mu \mathrm{g} / \mathrm{dL}$ and it was higher than that of the technicians in the roadside setting $49.5 \pm 9.6 \mu \mathrm{g} / \mathrm{dL}$. Finding show that there was a significant association between safety practices on lead poisoning at the workplace and blood lead levels at $X^{2}=24.760, \mathrm{df}=4, p<0.000$ and $95 \%$ confidence interval.

\subsection{Perceived Risk and Utilization of PPE}

Table 4 indicated that perceived risk associated with lead poisoning and utilization of PPE at the workplace was not significant for battery technicians in both organized and roadside setting as the statistical findings shows with $X^{2}=$ $0.150, \mathrm{df}=1, p>0.698$, and $X^{2}=8.716$, df $=1, p>0.065$ respectively. Moreover, Nagelkerke pseudo- $\mathrm{R}^{2}$ indicated a low goodness of fit as the model accounted for approximately $70 \%$ of the variance in the organized setting. 
Similarly, in the roadside setting, Nagelkerke pseudo- $\mathrm{R}^{2}$ indicated a low goodness of fit as the model accounted for

$52 \%$ of the variance.

Table 1. Descriptive analysis results of battery technicians demographic and occupational characteristics Lagos, Nigeria, January 2017.

\begin{tabular}{|c|c|c|c|c|}
\hline \multirow{2}{*}{ Variable } & \multirow{2}{*}{$\begin{array}{l}\text { Workshop } \\
\text { Organized }(n=148) \text { Freq. }(\%) \\
\end{array}$} & \multirow{2}{*}{$\begin{array}{l}\text { setting } \\
\text { Roadside ( } n=145) \text { Freq. (\%) }\end{array}$} & \multirow{2}{*}{$N=293(\%)$} & \multirow{2}{*}{$\begin{array}{l}\text { Statistical analysis } \\
p \text {-value }\end{array}$} \\
\hline & & & & \\
\hline \multicolumn{5}{|l|}{ Age group (years) } \\
\hline$<20$ & $0(0.0)$ & $01(0.34)$ & $01(0.34)$ & \multirow{6}{*}{$p<0.000$} \\
\hline $20-29$ & $22(7.51)$ & $27(9.22)$ & $49(16.72)$ & \\
\hline $30-39$ & $49(16.72)$ & $45(15.36)$ & $94(32.08)$ & \\
\hline $40-49$ & $61(20.82)$ & $59(20.14)$ & $120(40.96)$ & \\
\hline $50-59$ & $13(4.44)$ & $08(2.73)$ & $21(7.17)$ & \\
\hline$>60$ & $03(1.02)$ & $05(1.71)$ & $08(2.73)$ & \\
\hline \multicolumn{5}{|l|}{ Gender } \\
\hline Male & $148(100)$ & $145(100)$ & 293(100) & \\
\hline Female & $0(0.0)$ & $0(0.0)$ & $0(0.0)$ & \\
\hline \multicolumn{5}{|l|}{ Marital status } \\
\hline Married & $127(86.0)$ & $129(89.6)$ & $260(88.5)$ & \multirow{5}{*}{$p<0.001$} \\
\hline Divorced & $03(2.0)$ & $01(0.7)$ & $04(1.4)$ & \\
\hline Widow & $07(4.5)$ & $02(1.4)$ & $05(1.8)$ & \\
\hline Separated & $02(1.4)$ & $01(0.7)$ & $03(1.0)$ & \\
\hline Single & $09(6.1)$ & $12(8.3)$ & $21(7.3)$ & \\
\hline \multicolumn{5}{|l|}{ Education level } \\
\hline No formal education & $05(3.4)$ & $09(6.2)$ & $14(4.8)$ & \multirow{6}{*}{$p<0.000$} \\
\hline Elementary school & $35(23.6)$ & $43(29.7)$ & $78(26.6)$ & \\
\hline Some high school & $19(12.8)$ & $23(15.9)$ & $42(14.4)$ & \\
\hline High school graduate & $83(56.1)$ & $68(46.9)$ & $151(51.5)$ & \\
\hline Some College/Technical & $05(3.4)$ & $02(1.3)$ & $07(2.4)$ & \\
\hline University/college graduate & $01(0.7)$ & $0(0.0)$ & $01(0.3)$ & \\
\hline \multicolumn{5}{|l|}{ Monthly income (Naira) } \\
\hline$<20,000$ & $17(11.5)$ & $23(15.9)$ & $40(13.7)$ & \multirow{4}{*}{$p<0.042$} \\
\hline $21,000-40,000$ & $95(64.2)$ & $97(66.9)$ & $192(65.6)$ & \\
\hline $41,000-60,000$ & $34(22.9)$ & $24(16.6)$ & $58(19.7)$ & \\
\hline $61,000-80,000$ & $02(1.4)$ & $01(0.6)$ & $03(1.0)$ & \\
\hline \multicolumn{5}{|l|}{ Years of experience } \\
\hline$<5$ & $13(8.8)$ & $09(6.2)$ & $22(7.5)$ & \multirow{5}{*}{$p>0.923$} \\
\hline 5-9 & $15(10.1)$ & $17(11.7)$ & $32(10.9)$ & \\
\hline $10-14$ & $54(36.5)$ & $56(38.6)$ & $110(37.5)$ & \\
\hline $15-19$ & $37(25.0)$ & $35(24.2)$ & $72(24.6)$ & \\
\hline$>20$ & $29(19.6)$ & $28(19.3)$ & $57(19.5)$ & \\
\hline
\end{tabular}

Note.. EET $=$ Fisher's Exact Test, $p<0.05$ significant at $95 \% \mathrm{CI}=$ confidence interval, Freq $=$ Frequency, $\%=$ percent

Table 2. Multiple logistic regression analysis results of battery technicians' workplace conditions associated with lead poisoning safety practices (SAFETY) Lagos, Nigeria, January 2017

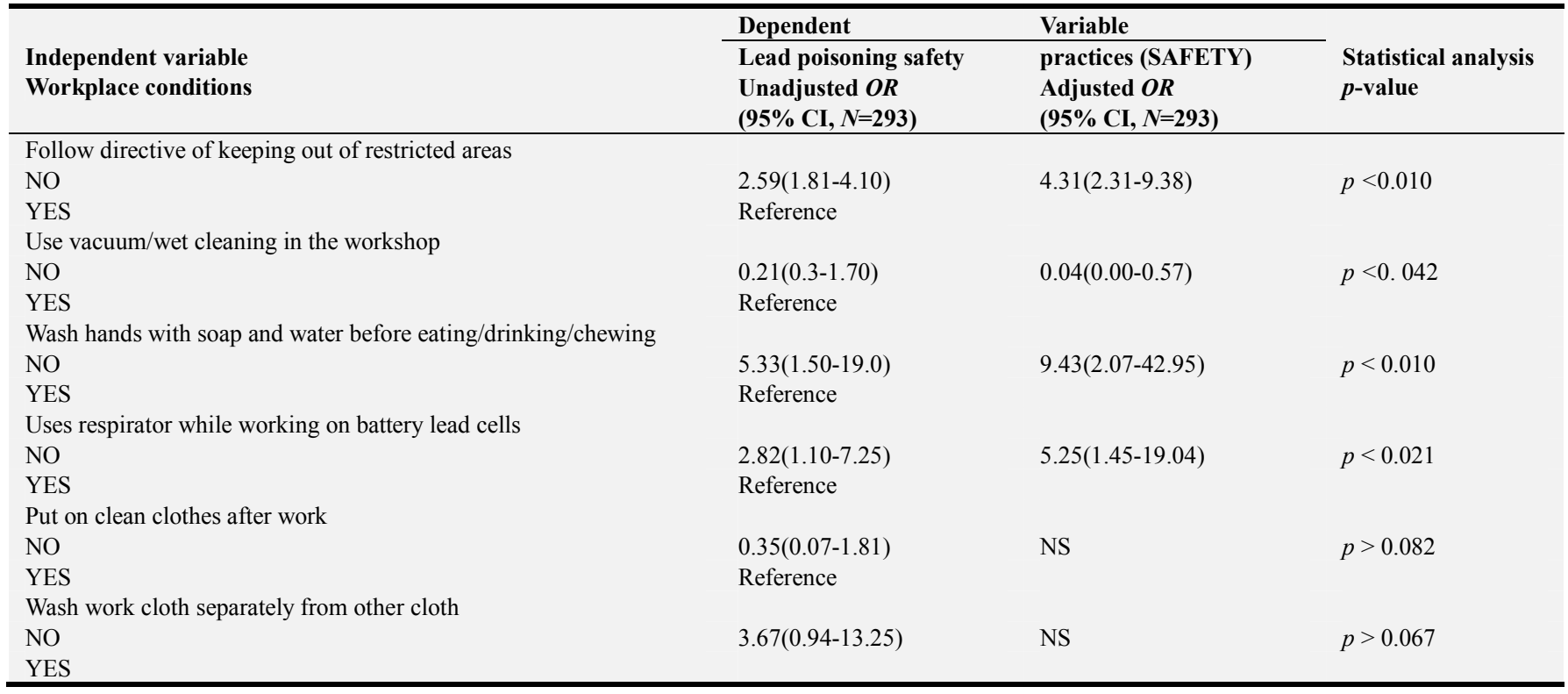




\begin{tabular}{|c|c|c|c|}
\hline & Dependent & Variable & \\
\hline $\begin{array}{l}\text { Independent variable } \\
\text { Workplace conditions }\end{array}$ & $\begin{array}{l}\text { Lead poisoning safety } \\
\text { Unadjusted } O R \\
(95 \% C I, N=293) \\
\end{array}$ & $\begin{array}{l}\text { practices (SAFETY) } \\
\text { Adjusted } O R \\
(\mathbf{9 5 \%} \mathrm{CI}, N=\mathbf{2 9 3}) \\
\end{array}$ & $\begin{array}{l}\text { Statistical analysis } \\
p \text {-value }\end{array}$ \\
\hline $\begin{array}{l}\text { Wears overall clothes to protect body from lead dust/solution } \\
\text { NO } \\
\text { YES }\end{array}$ & $\begin{array}{l}7.41(2.23-24.60) \\
\text { Reference }\end{array}$ & $12.93(2.94-56.8)$ & $p<0.002$ \\
\hline $\begin{array}{l}\text { Have and follow code of safety practices at the workplace } \\
\text { NO } \\
\text { YES }\end{array}$ & $\begin{array}{l}5.55(2.23-13.87) \\
\text { Reference }\end{array}$ & $6.35(2.31-17.42)$ & $p<0.001$ \\
\hline $\begin{array}{l}\text { Monitoring and visitation of workplace by inspector } \\
\text { NO } \\
\text { YES }\end{array}$ & $\begin{array}{l}1.75(0.94-14.25) \\
\text { Reference }\end{array}$ & NS & $p>0.635$ \\
\hline $\begin{array}{l}\text { Boss talks about lead poisoning safety at the workplace } \\
\text { NO } \\
\text { YES }\end{array}$ & $\begin{array}{l}11.20(1.43-102.70) \\
\text { Reference }\end{array}$ & NS & $p>0.085$ \\
\hline
\end{tabular}

Note. $p<0.05$ was considered significant at $95 \% \mathrm{CI}=$ confidence interval, $\mathrm{OR}=$ odds ratio, $A O R=$ adjusted odds ratio. Model adjusted for all covariate variables (age, education, year of experience, monthly income, and availability of safety equipment, and knowledge of lead poisoning safety practices), NS: Not Significant.

Table 3. Two-way chi-square analysis results of battery technician's blood lead levels and safety practices on lead poisoning Lagos, Nigeria, January 2017.

\begin{tabular}{|c|c|c|c|c|}
\hline \multirow[b]{2}{*}{ Blood lead levels } & Lead poisoning & safety practices & \multirow[b]{2}{*}{$N=293(\%)$} & \multirow[b]{2}{*}{$\begin{array}{l}\text { Statistical analysis } \\
X^{2} p \text {-value }\end{array}$} \\
\hline & $\begin{array}{l}\text { Poor practices } \\
(<50 \%) \text { Freq. }(\%)\end{array}$ & $\begin{array}{l}\text { Good practices } \\
(\geq 70 \%) \text { Freq. }(\%)\end{array}$ & & \\
\hline$\leq 5$ & 09(3.07) & $17(5.8)$ & $26(8.87)$ & 24.760 \\
\hline $6-40$ & $128(43.69)$ & $07(2.39)$ & $135(46.08)$ & $P<0.000$ \\
\hline $41-80$ & $50(17.06)$ & $08(2.73)$ & $58(19.8)$ & \\
\hline$\geq 81$ & $23(7.85)$ & $06(2.05)$ & $29(9.9)$ & \\
\hline No idea & $40(13.65)$ & $05(1.71)$ & $45(15.36)$ & \\
\hline Total & $262(85.32)$ & $31(14.68)$ & $293(100)$ & \\
\hline
\end{tabular}

Note. $p<0.05$ was considered significant at $95 \% \mathrm{CI}=$ confidence interval, Freq. $=$ frequency, $\%=$ percent

Table 4. Classification table of battery technicians perceived risk and utilization of PPE in the organized and roadside settings Lagos, Nigeria, January 2017.

\begin{tabular}{llll}
\hline \multirow{2}{*}{ Observed } & Predicted & & \\
\cline { 2 - 4 } & Unprotected & Utilize PPE & Percentage correct \\
\hline Unprotected & 85 & 11 & $88.7 \%$ \\
Utilized PPE & 08 & 42 & $84.3 \%$ \\
Overall & $86.0 \%$ & & \\
percentage & & & \\
\hline
\end{tabular}

Note.PPE: personal protective equipment, this Table was derived from $2^{\text {nd }}$ classification

output that accounts for the iv's and give information for the percentage gained.

\section{Discussion}

The analysis of this survey data revealed low safety practices status of $20 \%$ on lead poisoning at the workplace of battery technicians while the rate of utilization of PPE is $18 \%$ The safety practices status of battery technicians in Lagos, Nigeria is yet to reach the occupational health services and practice stipulated target of $90 \%$ compliance [16]. The rate of utilization of PPE at workplace could be considered as the prime index of safety practices performance evaluation; so, the low rate observed in this study could not make the desired impact on safety practices compliance [17]. For a developing country like Nigeria where change of work to reduce the potential for lead poisoning exposure is not certain among self-employed workers, then, improvement on safety practices is recommended $[18,19]$. The workplace of battery technicians could be reorganized to avoid a non-fit environment that could expose workers to lead hazards [20]. The self-protective behavioral practices could be improved by imbibing positive behavioral attitudes towards safety practices [21]. There is need for battery technicians to improve on personal hygiene by washing their hand and face with soap and water before eating, drinking or smoking as this act is vital to safety practices on lead poisoning, since oral ingestion is one of the 3 major routes of exposure [22]. Haider and Qureshi [7] stated that the second route of exposure to lead contaminants is through inhalation. Lead fumes inhalation occurs if there is no proper ventilation or there is lack of decontamination services at the workplace. Then, the use of safety equipment and personal hygiene is emphasized to offer self-protection against lead poisoning. Compliance with utilization of safety facilities at the workplace is one of the prime indexes of assessing the safety practice performance of workers who were exposed to occupational hazard [23]. Also, improper or lack of adequate control measures, non-provision of safety equipment, lack of monitoring, lack of safety training, and lack of health check by battery technicians are safety practices quality indices on lead poisoning [24, 25]. Multilevel factors that determine the safety practices on lead poisoning are the enabling environment and availability of PPE (like protective cloth, eye goggle, hand glove, respirator, nose mask and protective shoes), safety facilities, communication, and training on how 
to use the PPE [26]. Kalahasthi et al. [27] stated that one of the reasons for non-compliance with safety practices is poor communication and lack of enforcement on the part of the safety inspectors who were saddled with the responsibility. The occupational lead exposure in many developing countries is entirely unregulated at the workplace of selfemployed technicians [27]. Therefore, an appropriate, costeffective integrated preventive and control measures is required in the workplace of battery technicians in Nigeria. Harnessing safety system could improve the workplace conditions and facilitate compliance with safety practice on lead poisoning [28].

The mean blood lead levels of battery technicians' reported in this study for the organized setting was $61.2 \pm 13.6 \mu \mathrm{g} / \mathrm{dL}$ and it was higher than that of the battery technicians in the roadside setting $49.5 \pm 9.6 \mu \mathrm{g} / \mathrm{dL}$. Were et al. [29] examined factors that influence blood lead levels and safety practices among the lead battery plants workers who were exposed to lead pollutants in Kenya. The finding of the study is consistent with that of this study as the blood lead levels of the technicians were found to be high for those in lead exposed industrial plants. The analysis of perceived risk associated with the exposure to lead poisoning and use of PPE at the workplace was not significant for battery technicians in both organized and roadside setting with $X^{2}=$ $0.150, \mathrm{df}=1, p>0.698$ and $X^{2}=8.716, \mathrm{df}=1, p>0.065$ respectively. Therefore, lack of information on safety practices could affect the perceived risks and low utilization of the PPE in both settings [30, 31]. The Dejoy theory applied to this study concluded that behavior is impacted and this could, in turn, impacts intrapersonal, interpersonal, social support and social policy [32]. The Guttman scale was used to grade the response in the instrument and it was scaled from $0-1$. The limitation of this scale is that the standard used for the determination of the code " 0 " and " 1 " could be high to exclude few weak probable positive responses. Also, lack of data on environmental monitoring is a limitation for this study. All these factors could limit the generalizability of the findings to the entire population of battery technicians in Nigeria. There is a realization that battery technicians' safety practices status is positively associated with the workplace conditions, self-protective behavior, and utilization of PPE at the workplace. It is imperative to recommend provision of hand washing stand with soap and water as an alternative measure towards safety practice at the workplace. Furthermore, use of protective cloth and face mask could be made compulsory at the workplace to protect dermal absorption and inhalation of lead contaminants. These safety appliances are not expensive even for self-employed battery technicians studied. The outcome of this study had shown that battery technicians' rate of utilization of PPE predicts the safety practices status. Also, there is no difference in the rate of utilization of PPE among battery technicians in the organized and roadside setting. A follow up study of the subjects is recommended to establish whether the suggestions on safety practices are implemented. The occupational safety inspectorate unit in Nigeria could strategize and plan regular monitoring, and enforcement of safety policy at the workplace of battery technicians. Finally, lead safety initiative program is recommended and to be planned and focus lead hazard reduction at workplace of battery technicians.

\section{Conclusion}

Since the positive social change implication of this study is to reduce the morbidity, disabilities, and mortality that were associated with lead poisoning. Therefore, improvement of workplace condition and access to information on safety practices could be addressed. Also, safety practices could be improved by directing efforts towards training of battery technicians on personal hygiene and the need to comply with safety measures at the workplaces.

\section{Author's Contribution}

TOR: Design and conceptualized the study, analyzed data NM: Wrote abstract and conclusion of the study

WAA: Proof read the manuscript

ROA: Coordinated data entry into computer statistical software.

\section{Conflict of Interest}

All the authors do not have any possible conflicts of interest.

\section{References}

[1] Gottesfeld P, Pokhrel AK. Review: Lead exposure in battery manufacturing and recycling in developing countries and among children in nearby communities. J of Occup and Environ Hygiene. 2011; 8(9): 520-32. doi:

$10.1080 / 15459624.2011 .601710$

[2] Center for Disease Control and Prevention [CDC]. Health problem caused by exposure to lead. 2014; https://www.cdc.gov/niosh/topics/lead/health.htm. Accessed February 12, 2017

[3] International Labor Organization [ILO]. Promoting jobs, protecting people; Occupational safety and health. 2012; http://www.ilo.org/global/topics/safety-and-health-atwork/lang--en/index.htm. Accessed January 18, 2017

[4] WHO/ Lead poisoning and health. 2014; 1-4. http://www.who.int/mediacentre/factsheets/fs379/. Accessed February 10, 2017

[5] Huang W, Lin J, Lin-tan D, Hsu C, Chen K, Yen T. Environmental lead exposure accelerates progressive diabetic nephropathy in type II diabetic patients. Biomed Research Internatl J. 2013; 1-9. http://dx.doi.org/10.1155/2013/742545

[6] Adela Y, Ambelu A, Tessema DA. Occupational lead exposure among automotive garage workers- A case study for Jimma Town, Ethiopia. J of Occup Medicine and Toxicology. 2012; 7(1): 1-15.doi:10.1186/1745-6673-7-15 
[7] Haider MJ, Qureshi N. Studies of battery repair and recycling workers occupationally exposed to lead in Karachi. Natl. Inst. of Public Health. 2013; 64(1): 37-42. PMID: 23789311 [PubMed - indexed for MEDLINE]

[8] Abdulsalam S, Onajole A, Odeyemi K, Ogunowo B, Abdussalam I. Comparative assessment of blood lead levels of automobile technicians in organized and roadside garages in Lagos, Nigeria. J of Environ and Public Health. 2015; 2(7): 19. http://dx.doi.org/10.1155/2015/976563

[9] Perry G, Amod KP. Review of lead exposure in battery manufacturing and recycling in developing countries and among children in nearby communities. $\mathrm{J}$ of Occup and Environ Hygiene. 2011; 8(9): 520-532. doi: $10.1080 / 15459624.2011 .601710$

[10] Dongre NN, Suryakar AN, Patil AJ, Amekar JG, Rathi DB. Biochemial effects of lead exposure on systolic \& diastolic blood pressure, hemebiosynthesis and hematological parameter in automobile workers of north Karnataka (India). India $\mathrm{J}$ of clinical Biochem. 2011; 26(4):400-406. doi:10.1007/s12291-011-0159-6

[11] National Institute for Occupational Safety and Health [NIOSH]. Reference blood lead levels (BLL) for adults in the U.S. 2015; https://www.cdc.gov/niosh/topics/ables/pdfs/Reference\%20B1 ood\%20Levels\%20for\%20Adults-2015-12-18_508.pdf. Accessed February 12, 2017

[12] Centers for Disease Control and Prevention. Case definition for lead: Nationally notifiable conditions. Atlanta, GA: Centers for Disease Control and Prevention. 2016; https://wwwn.cdc.gov/nndss/conditions/lead-elevated-bloodlevels/case-definition/2016/. Accessed February 12, 2017

[13] Peduzzi P, Concato J, Kemper EA. simulation study of the number of events per variable in logistic regression analysis. $\mathrm{J}$ of Clinical Epidemiology. 1996; 49(12): 1373-1379. https://www.ncbi.nlm.nih.gov/pubmed/8970487. Accessed February 14, 2017

[14] Rudestam K E, Newton RR. Surviving your dissertation: A comprehensive guide to content and process. (4th Ed.). Thousand Oaks, CA: Sage Publications. 2015

[15] Field A. Discovering statistics using IBM SPSS statistics. (4th Ed.) London: Sage. 2013

[16] Occupational Health Services and Practice [OHSP]. 2013; http://www.ilocis.org/documents/chpt16e.htm. Accessed February 15, 2017

[17] Alberta Occupational Health and Safety Bulletin [AOHS]. 2013; https://work.alberta.ca/occupational-health-safety/ohspublications.html. Accessed February 15, 2017

[18] Kuijp TJ, Huang L, Cherry CR. Health hazards of China's lead-acid battery industry: A review of its market drivers, production processes, and health impacts. Environtal Health J.2013; 12(61): 1-10. doi:10.1186/1476-069X-12-61

[19] Pogacean OA, Gurzau ES. Workers exposure and individual behavior in a car battery plant. Indian J of Research. 2014; 3(11):73-75.doi: 10.15373/22501991/November2014/27

[20] Ajugwo AO, Adias TC, Aghatise K, Fadairo JK, Nyenke CU. Reduced haematological indices in auto-mechanics and fuel attendants in Elele Nigeria. American J of Medical and Biological Research. 2014; 2(1): 1-4. doi.10.1110.11694/pamj.supp.2014.18.1.4264

[21] Patil AJ, Bhagwat VR, Patil JA, et al. Biochemical aspects of lead exposure and toxicity in spray painters of western Maharashtra (India). J of Environ Health Research. 2013; 6(2):101-110

https://www.researchgate.net/profile/Vinod_Bhagwat/publicat ion/235326905. Accessed February 18, $201 \overline{7}$

[22] Riva MA, Lafranconi A, D'orso MI, et al. Lead poisoning: historical aspects of a paradigmatic "occupational and environmental disease"; Research centre on public health, University of Milano Bicocca, Monza, Italy. Safety Health Workers J. 2012; (3): 11-6. http://dx.doi.org/10.5491/SHAW.2012.3.1.11

[23] Ahmad SA, Khan MH, Khandker S, et al. Blood lead levels and health problems of lead acid battery workers in Bangladesh. The Scientific World J. 2014; (2014): 1-7. http://dx.doi.org/10.1155/2014/974104

[24] Pogacean OA, Pop C. Potential hand - to - mouth exposure to lead in a car battery factory. Wulfenia J Austria. 2015; 22(5): 83-90. http://www.researchgate.net/publication/275962767. Accessed February 19, 2017

[25] Kalahasthi R, Barman T, Rao HR. Assessment of the relationship between blood lead levels and hematological parameters among lead acid storage battery plant workers. J of Occup and Environ Science. 2012; 1(1): 1-5. doi:10.5455/joes/20120602121627

[26] Monney I, Bismark D, Isaac O, Kuffour RA. Occupational health and safety practices among vehicle repair artisans in an urban area in Ghana. J of Environ and Occup Science. 2014; 1-8. doi:10.5455/jeos.20140528072614

[27] Kalahasthi R, Barman T, HR R, Bagepally B S, Beerappa R. Effectiveness of interventions on biological monitoring among workers exposed to $\mathrm{Pb}$ from lead-acid Storage battery plant. Internatl J of Medical Science and Public Health, 2016; 1(09): 1-5. doi:10.5455/ijmsph.2016.19112015318

[28] Liao LM. Friesen MC, Xiang Y, et al. Occupational lead exposure and associations with selected cancers: the Shanghai men's and women's health study cohorts. Environ Health Perspective. 2016; 124(1): 97-103. doi:10.1289/ehp.1408171

[29] Were FH, Moturi MC, Gottesfeld P, Wafula GA, Kamau GN, Shiundu PM. Lead exposure and blood pressure amongworkers in diverse industrial plants in Kenya. $\mathrm{J}$ of Occup and Environ Hygiene. 2014; 11(11): 706-15.doi: $10.1080 / 15459624.2014 .908258$

[30] Tuakuila J, Lison D, Mbuyi F, Haufroid V, Hoet P. Elevated blood lead levels and sources of exposure in the population of Kinshasa, the capital of the Democratic Republic of Congo. J of Exposure Science and Environ Epidemiology. 2013; 23: 81-87. doi: $10.1038 /$ jes.2012.49

[31] Mason LH, Harp JP, Han DY. Pb neurotoxicity: neuropsychological effects of lead toxicity. Biomed Research Internatl J. 2014; 1-8. http://de.doi.org/10.1155/2015/840547

[32] Dejoy DM. Theoretical model of health behavior and workplace self-protective behavior. J of Safety Research. 1996; 27(2): 61-72.

http://158.132.155.107/posh97/private/behavioralsafety/theoretical-models-DeJoy.pdf/2013/219840. Accessed February 20, 2017 